\title{
Corrosion inhibition of mild steel in seawater through green approach using Leucaena leucocephala leaves extract
}

\author{
W.M.K.W.M. Ikhmal, ${ }^{1,2}$ M.F.M. Maria, ${ }^{1,2}$ W.A.W. Rafizah,, \\ W.N.W.M. Norsani ${ }^{2,3}$ and M.G.M. Sabri ${ }^{1,2,4 *}$
}

${ }^{1}$ Advanced Nano Materials (ANoMa) Research Group, School of Fundamental Science, Universiti Malaysia Terengganu, 21030 Kuala Nerus, Terengganu, Malaysia

${ }^{2}$ Materials and Corrosion Research Group, Universiti Malaysia Terengganu,

21030 Kuala Nerus, Terengganu, Malaysia

${ }^{3}$ School of Ocean Engineering, Universiti Malaysia Terengganu, 21030 Kuala Nerus,

Terengganu, Malaysia

${ }^{4}$ Institute of Biodiversity and Sustainable Development, Universiti Malaysia Terengganu,

21030 Kuala Nerus, Terengganu, Malaysia

*E-mail: mohdsabri@umt.edu.my

\begin{abstract}
Corrosion inhibition analysis of Leucaena leucocephala leaves extract (LLE) as an additive incorporated into a commercialized coating to protect mild steel when immersed in seawater has been successfully conducted. The procedures involve the utilization of multiple techniques including Fourier transform infrared spectroscopy (FTIR), ultravioletvisible spectroscopy (UV-Vis), electrochemical impedance spectroscopy (EIS), potentiodynamic polarization and scanning electron microscope with energy-dispersive $\mathrm{X}$ ray spectroscopy (SEM/EDS). The result of FTIR identified both hydroxyl $(-\mathrm{OH})$ and carbonyl $(\mathrm{C}=\mathrm{O})$ groups indicating the presence of phenolic compounds in the extract whereas the analysis obtained from UV-Vis showed a peak absorption spectrum at $268 \mathrm{~nm}$. The electrochemical analysis indicated an excellent inhibition efficiency up to $96.12 \%$ for the immersed mild steel coated with $6 \%$ of LLE coating. Furthermore, based on the study of polarization, a drastic decrease of corrosion rate at $0.2791 \mathrm{~mm} /$ year was observed for the same coating as compared to the uncoated substrate, which was $2.3991 \mathrm{~mm} /$ year. The study also confirmed that LLE acts as a mixed type inhibitor, as shown in the polarization curve. The morphological evaluation displayed a smooth and homogenous surface with less salt precipitation for $6 \%$ of LLE coating as compared to other types of coating affirming it to be the optimum concentration for this evaluation study.
\end{abstract}

Keywords: stainless steel, corrosion, coating, seawater, plant extract.

Received: July 25, 2019. Published: August 15, 2019

doi: $\underline{10.17675 / 2305-6894-2019-8-3-12}$ 


\section{Introduction}

Corrosion is a global issue affecting mostly on metal-based materials through the degradation process. In industries, the consequences of neglecting corrosion will not only result in the loss of material's value but may eventually lead to a total failure of a particular system [1]. Such adverse outcomes moreover can be seen to be accelerating when certain conditions are met. One of the situations is the exposure of metals to a salt-containing solution, i.e. mild steel immersed in the seawater. Classified as an unnatural type of corrosion, the circumstance is due to seawater contains a lot of dissociated ions where it will increase the conductivity of the solution and hence, hasten the process of corrosion on the metal surface [2]. As such, the impacts of corrosion on the marine industry such as the oil and gas industry is actually on a larger scale compares to other since the primary engineering materials of most marine installation components are made up of metals [3]. Globally and historically, multiple solutions have been introduced in pursuit to eradicate or slow down the process of corrosion. Five of the most common corrosion control practices are material selection, coating, inhibitor, cathodic protection, and design [4]. Although each means has its pros and cons, current research has long shifted towards the development of an excellent counter-measure by utilizing the beneficial property of different parts of plants [5-11]. The shift of interest occurred when the previous corrosion reducing agents are found to possess harmful effects on both the environment and human health [12].

Back in the 1990s, inhibitors derived from organic and inorganic compounds are commercialized and widely applied. However, the discovery which leads to the banning and restriction of inhibitor developed using an inorganic material containing tungstate, phosphate, chromate, and heavy-based metals forced the researchers to find an alternative solution. Furthermore, the use of several organic inhibitors such as triazole, hydrazine, benzotriazole, and thiourea through the adsorption process on the metal surface are unfortunately also found to pose threats since studies showed that it has the harmful properties of being toxic and non-biodegradable to a certain extent [13-16]. Therefore, inhibitor derived from natural products has recently been selected to be the next major route in this regards as it has the advantages of being environmentally-friendly, biodegradable, renewable, cheaper and can be easily accessible while providing an excellent corrosion inhibition capability [17].

Leucaena leucocephala or commonly identified as river tamarind and jumbay is a type of mimosoid tree which grows in tropics region of the world. The tree which is capable of living for a long time is also known for its nutritious value and in fact term as the 'miracle tree' in few regions of the globe. Originated from southern Mexico and northern Central America, river tamarind was first discovered by Spaniards more than 400 years ago and since then spreads widely as a shade plant for plantation crops [18]. Characteristically, the trees of Leucaena leucocephala averagely grown up to 2-10 $\mathrm{m}$ tall with stern and branches previously found to be suitable as biofuel for purposes of heat and 
electricity production [19]. The plant is also famous for its medicinal value due to the high amount of $\beta$-carotene, vitamin $\mathrm{K}$, and $\beta$-carotene, which can be found almost in all parts of the tree [20]. In one of the study explicitly conducted to analyze the secondary metabolites present in the leaves part of a sample from Malaysia, the results show that the leaves contain diterpene, triterpene, palmitic acid, terpene alcohol, linolenic acid ester and dicarboxylic acid where most of these metabolites identified are actually known for their activity of antioxidant, antibacterial, anti-inflammatory, antitumor and anticancer [21]. Hence, in this study, the research will be conducted based on anti-oxidation property mentioned before to investigate the capability of its leaves extracts in enhancing the ability of an amine adduct cured epoxy coating to reduce corrosion rate on the surface of mild steel in a closed system.

Mild steel or also known as low-carbon steel due to the amount of carbon within it is less than the typical commercialized carbon steel is regarded as one of the most popular materials used for the works of fabrication in multiple industries ranging from its usage in constructing pipelines to the nuclear application [22]. The low level of carbon contains within it makes the material to be both malleable and ductile while capable of undergoing the processes of hardening and tempering for a wide range of application. On top of that, mild steel possesses good mechanical strength, high thermal and electrical conductivity, easy to obtain, and low in cost [23]. However, in terms of fighting against corrosion when exposed to corrosive environments, mild steel is considered to be relatively weak. The state is much plainer to be seen with naked eyes when mild steel is exposed to a chloridecontaining medium such as seawater. Upon subjected to such condition, localized corrosion or specifically oxygen absorb corrosion will be initiated on its surface. It is a type of corrosion where the presence of chloride ions will cause the protective hydrogen film or passive film to break down in a short period.

As one of the general corrosion control practices, the coating has proved its capability to reduce the issue on both closed and open system. Defined as a layer which covers a surface known as the substrate, the coating is commonly applied for various aims such as to improve the outlook of a product, providing a specific function such to protect the metal from corroding or both [24-27]. The selected coating, EA9 Finish HB is a type of amine adduct cured epoxy coating commercialized for protection on aluminum, steel, and concrete. The paint finish can be easily applied using brush or roller and generally mix with hardener to enhance the matrix structure [28]. In this study, the scope of the project is to upgrade the performance of EA9 Finish HB by incorporating the leaves extract of Leucaena leucocephala. The notion is highlighted since the previous study suggested that the incorporation of natural plant extract in the coating can produce significant positive differences [29]. Thus, the study aims to discover the extent of the capability of a local herb which is Leucaena leucocephala or 'petai belalang' when introduced as an additive into a commercialized coating matrix and how will it improved the coating performance in dealing with seawater. 


\section{Materials and Methods}

\subsection{Chemicals}

Dry leaves powder of river tamarind was bought from Secret Barn Sdn. Bhd. and 80\% ethanol was supplied by Universiti Malaysia Terengganu. EA9 Finish HB, hardener and general thinner were acquired from a local Nippon Paint shop situated in Kuala Nerus, Terengganu, Malaysia.

\subsection{Preparation of Leucaena leucocephala leaves extract}

The extraction of Leucaena leucocephala leaves extract began by soaking the dry powder in $80 \%$ ethanol. $10 \mathrm{~g}$ of dry powder was macerated in $100 \mathrm{ml}$ of $80 \%$ ethanol based on the ratio of 1:10. Mixed powder in a conical flask was then placed on a shaker and shook for about 4 hours to increase the maceration efficiency until it homogeneously dissolved. Next, the dissolved mixture was filtered using Whatman no. 1 filter paper and evaporated using rotary evaporator. The residue left within the container, which was also known as the crude extract was stored in vial bottles and put in a refrigerator $\left(4^{\circ} \mathrm{C}\right)$ until the next procedure.

\subsection{Characterization of extract}

\subsubsection{Fourier transform infrared (FTIR) spectroscopy}

The diluted crude extract of the leaves of Leucaena leucocephala was subjected to infrared analysis by Alvatar Nicolet 380 FTIR spectrometer to identify the functional groups present within it. The FTIR analysis was recorded between $500-400 \mathrm{~cm}^{-1}$ of the wavelength region since most of the absorption radiation of organic compounds fall in this range [27]. The resolution was set at $16 \mathrm{~cm}$ for 40 scans for each sample analyzed.

\subsubsection{Ultraviolet-Visible (UV-Vis) Spectroscopy}

The absorption spectrum of a diluted crude extract of the leaves of Leucaena leucocephala was measured using an in-house built cell model of UV-Vis spectrophotometer (Lambda 265, Perkin Elmer) in the absorbance range of 200-800 nm.

\subsection{Preparation of Mild Steel}

Several pieces of mild steel were employed as the testing substrate in this study. Mild steels were cut into the dimension of $25 \mathrm{~mm} \times 25 \mathrm{~mm} \times 3 \mathrm{~mm}$ following ASTM E3-11. The steels were then polished under streaming water by using emerald paper of grades P240, P320, P600, P800, and P1000 to get a smooth and mirror-like surface. The polished samples were next greased with acetone for a few minutes, rinsed using distilled water before finally air-dried and stored individually in a package and placed in a dry box. 


\subsection{Formulation and Preparation of Coating}

The formulation for mild steel was formulated using several materials acting as the binder, pigment, additive, and solvent. Simple formulation based on previous studies was constructed as shown in Table 1. EA9 Finish HB with its hardener was selected for its commercialization purpose. The finish served as both binder and pigment. General thinner was chosen as the solvent, and Leucaena leucocephala leaves extracts as the additive which functioned as to enhance a specific attribute, in this case, anti-corrosion property. The mixture was stirred on a hotplate at room temperature until it was homogeneously dissolved. The finished product was sealed in a suitable container using parafilm and immediately applied on to the surface of the steel within 1 hour. Each substrate was first cleaned using acetone and air-dried prior to the coating process. The coating was applied using a thin brush carefully as to ensure it spread evenly on the surface of the steel with the average thickness of the coating was fixed to be in the range of $50 \pm 10 \mu \mathrm{m}$. Coated substrates were then air-dried for 2 hours before finally proceed to the immersion test.

Table 1. Coating formulation.

\begin{tabular}{cccc}
\hline EA9 Finish HB $(\mathbf{m l})$ & Hardener $(\mathbf{m l})$ & Extract $(\boldsymbol{\%})$ & General Thinner $(\mathbf{m l})$ \\
\hline 90 & 10 & 0 & 10 \\
90 & 10 & 3 & 10 \\
90 & 10 & 6 & 10 \\
90 & 10 & 9 & 10 \\
90 & 10 & 12 & 10 \\
\hline
\end{tabular}

\subsection{Immersion Test}

Several beakers with a fixed amount of seawater which was calculated based ASTM G3172 were prepared. The mild steels that have been coated with a different type of coating were suspended inside the beakers using strings. The immersion test was conducted for a duration of 240 hours where the beakers containing the coated mild steels were left inside a laboratory to avoid any unrelated disturbance. After the test was done, each mild steel was taken out and proceed to the analysis of impedance, and surface characterization.

\subsection{Electrochemical Measurements}

The study on the efficiency of the coating produced by means of electrochemical analysis was conducted via potentiodynamic polarization and electrochemical impedance spectroscopy (EIS). Measurements were conducted using Autolab PGSTAT302N where the data obtained were fitted and analyzed using NOVA 1.10 program. For the potentiodynamic polarization study, a standard conventional three electrodes corrosion cell was employed with the mild steel acting as the working electrode (WE), a platinum wire as 
the counter electrode and saturated calomel electrode (SCE) as the reference with a scanning rate of $10 \mathrm{mV} \mathrm{s}^{-1}$. The corrosion current density $\left(i_{\text {corr }}\right)$ measurement was calculated based on the Stern-Geary equation in Equation 1, where $b_{\mathrm{a}}$ represents the anodic Tafel slope, $b_{\mathrm{c}}$ as the cathodic Tafel slope and $R_{\mathrm{p}}$ as the polarization resistance:

$$
i_{\text {corr }}=\frac{b_{\mathrm{c}} b_{\mathrm{a}}}{2.303 R_{\mathrm{p}}\left(b_{\mathrm{c}}+b_{\mathrm{a}}\right)}
$$

As for the EIS measurement, the analysis was performed for the impedance measurement using alternating current (AC). The frequency used was in the range of 0.01 $\mathrm{Hz}$ to $10000 \mathrm{~Hz}$.

\subsection{Surface Characterization by SEM/EDS}

The surface morphology was studied using a SEM model JEOL JSM-6360LA to analyze the differences of mild steel surfaces with the presence and absence of coating with additional analysis of elemental distribution by energy-dispersive X-ray spectroscopy (EDS). Mild steel coupons which have been taken out from the beakers were dried at room temperature and then proceed to the coating of a thin gold particle layer to increase the observance efficiency. The scanning process was done by the magnification of $\times 500$ for flat surfaces and $\times 100$ for cross-sectional areas of coated and uncoated mild steels.

\section{Results and Discussion}

\subsection{Fourier Transform Infrared Spectroscopy (FTIR)}

The extract of river tamarind (Leucaena leucocephala) leaves was subjected to the FTIR analysis to get the basic understanding and ideas on the type of functional groups present. Figure 1 shows the spectrum of LLE where it can be observed that a strong and broad peak of $\mathrm{O}-\mathrm{H}$ stretching can be identified at $3363.86 \mathrm{~cm}^{-1}$ representing the compound class of alcohol. Another strong peak at $2975.16 \mathrm{~cm}^{-1}$ also indicates the same O-H stretching which belongs to the class of carboxylic acid. The additional peaks at $2345.44 \mathrm{~cm}^{-1}$ and $1647.21 \mathrm{~cm}^{-1}$ are due to the $\mathrm{O}=\mathrm{C}=\mathrm{O}$ stretching and $\mathrm{C}=\mathrm{C}$ stretching of carbon dioxide and alkene, respectively. It was also observed that two medium peaks at $1383.31 \mathrm{~cm}^{-1}$ and $1043.49 \mathrm{~cm}^{-1}$ are present due to $\mathrm{C}-\mathrm{H}$ bending and $\mathrm{C}-\mathrm{N}$ stretching which can be categorized in the class of alkane and amine, respectively. Finally, a class chemical compound assumedly belongs to benzene is determined at peak $877.61 \mathrm{~cm}^{-1}$ due to $\mathrm{C}-\mathrm{H}$ bending where it is also identified as 1,2,4-trisubstituted. 


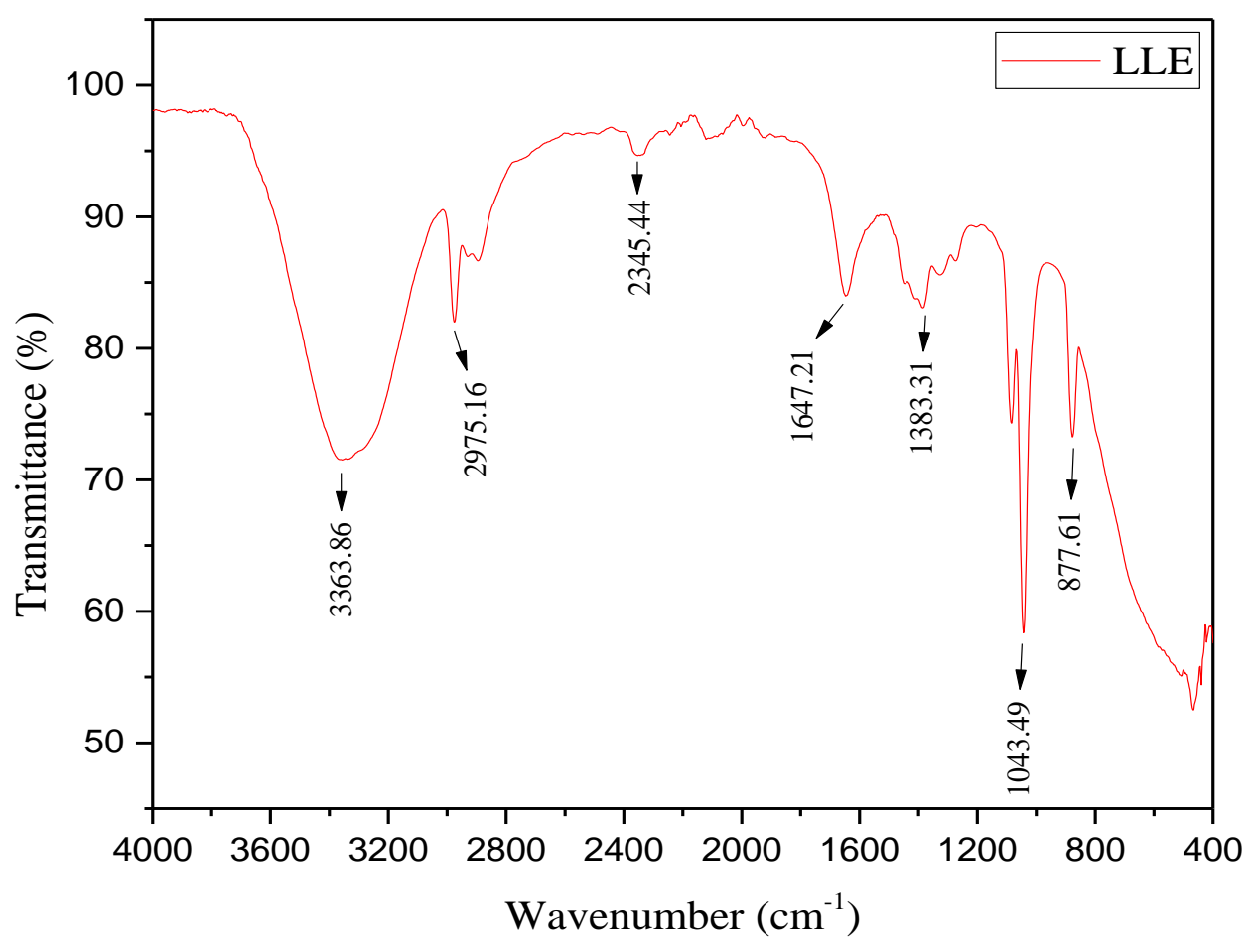

Figure 1. FT-IR spectrum of river tamarind leaves extract.

Table 2. FTIR absorption characteristics.

\begin{tabular}{ccccc}
\hline $\begin{array}{c}\text { Absorption } \\
\left(\mathbf{c m}^{-1}\right)\end{array}$ & Appearance & Group & Compound Class & Comment \\
\hline 3363.86 & Strong \& Broad & $\mathrm{O}-\mathrm{H}$ stretching & Alcohol & $\begin{array}{c}\text { Intermolecular bonded } \\
\text { Commonly centered } \\
\text { around } 3000 \mathrm{~cm}^{-1}\end{array}$ \\
2975.16 & Strong & $\mathrm{O}-\mathrm{H}$ stretching & Carboxylic Acid & - \\
2345.44 & Strong & $\begin{array}{c}\mathrm{O}=\mathrm{C}=\mathrm{O} \\
\text { stretching }\end{array}$ & Carbon Dioxide & Mono-substituted \\
1647.21 & Strong & $\mathrm{C}=\mathrm{C}$ stretching & Alkene & - \\
1383.31 & Medium & $\mathrm{C}-\mathrm{H}$ bending & Alkane & - \\
1043.49 & Medium & $\mathrm{C}-\mathrm{N}$ stretching & Amine & - \\
877.61 & Strong & $\mathrm{C}-\mathrm{H}$ bending & $\begin{array}{c}1,2,4- \\
\text { trisubstituted }\end{array}$ & - \\
\hline
\end{tabular}

\subsection{Ultraviolet-visible spectroscopy}

Figure 2 shows the schematic diagram for the absorbance obtained from the analysis of Ultraviolet-Visible (UV-Vis) spectroscopy on the leaves extract of Leucaena leucocephala. As a common method for the initial study of plant extract, UV-Vis is a reliable and excellent procedure for the prediction of compounds present in an extract. Based on 
Figure 2, the absorption spectrum of LLE indicates that compounds present display maximum absorption in the vicinities of $260-270 \mathrm{~nm}$ with the peak absorption was $268 \mathrm{~nm}$. Additionally, the graph also showed a small noticeable peak appearing at $665 \mathrm{~nm}$ which is in the region of red and near-infrared where it can be attributed to the chloroplast, a vital component for photosynthesis reaction in leaves.

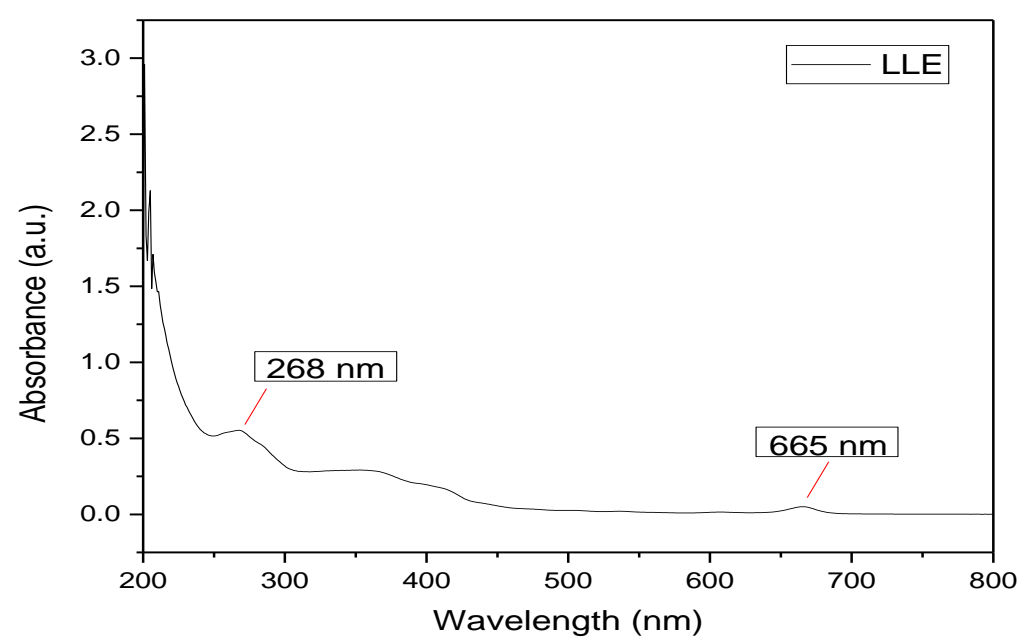

Figure 2. Absorption spectrum of river tamarind leaves extract.

\subsection{Electrochemical impedance measurement}

The Nyquist plots resulted from the analysis of EIS on coated and uncoated mild steel immersed in seawater for 240 hours at room temperature were shown in Figure 3. As a non-destructive method to analyze the corrosive behavior of a sample, the method can be used to assess the system stability. The graph is generally plotted with real impedance, $Z^{\prime}$ is assigned on the x-axis while imaginary impedance, $Z^{\prime \prime}$ on the y-axis. As plotted in Figure 3, these plots with imperfects semicircles can be attributed to the rough surface of mild steel since the coatings were only applied on one side leaving the other to corrode in continuous exposure drastically. Based on the obtained result, the corresponding parameter of charge transfer resistance, $R_{\mathrm{ct}}$ and inhibition efficiency, $\eta$ were also tabulated in Table 3. The variety of spectra can be ascribed to the different behavior of resistive and capacitive of the substrates according to the permeation of electrolyte ion on the surface of the coating. According to Figure 3, it can be assumed that the diameter of the imperfect semicircles increased with the increased concentration of LLE in the coating until a certain limitation is achieved. These suggest that the coating developed provides an excellent protective layer to slow down the corroding progress on the surface of mild steel since a considerable value of $R_{\mathrm{ct}}$ means a slower corrosion rate. The increase of $R_{\mathrm{ct}}$ showed that the corrosion progress at the interface between the coating is less susceptible. Generally, $R_{\mathrm{ct}}$ values tend to fall drastically during the initial stage of exposure of the coating to the aggressive solution. The phenomenon is due to the constant penetration of electrolytes into 
the coating matrix. As the immersion time is prolonged, the values will start to become stagnant since the coating is stabilized, and no more electrolytes can be absorbed. However, this state will begin to deteriorate after a certain period, and $R_{\mathrm{ct}}$ will fall again. During the last stage, the coating will peel off because of the extensive water accumulation under the coating layer. Additionally, from Figure 3, the shape of the semicircle shows no sign of changing, implying that the same mechanism occurs throughout the different type of coating. The inhibition efficiency continues to increase until it reached the value of $96.12 \%$ for $6 \%$ LLE coating and then started to fall, which acts as an indication that the optimum value has been obtained.

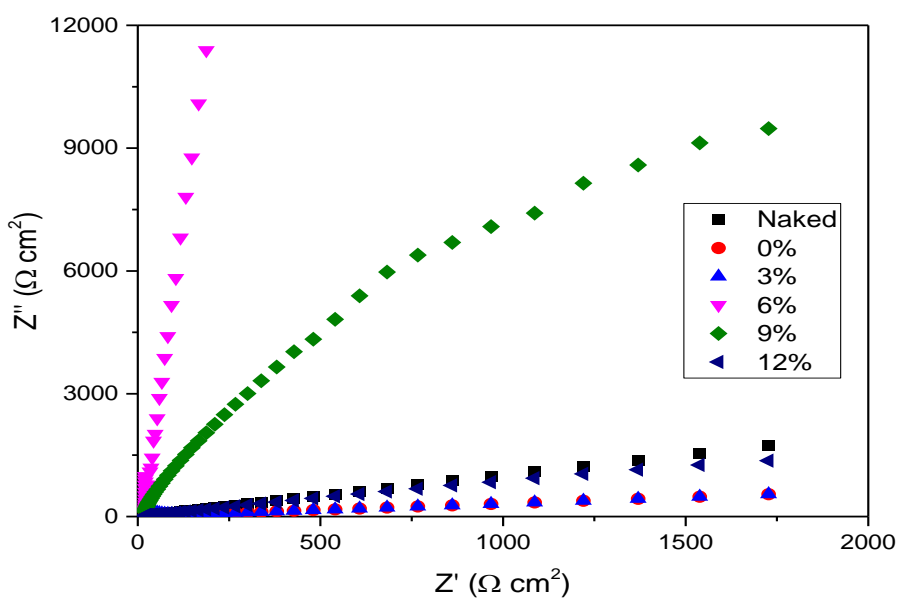

Figure 3. Nyquist plot for coated and uncoated mild steels immersed in seawater.

Table 3. Impedance parameters of mild steel immersed in seawater.

\begin{tabular}{ccc}
\hline Coating $(\%)$ & $\boldsymbol{R}_{\mathrm{ct}}\left(\mathbf{\Omega} \mathbf{~ c m}^{\mathbf{2}}\right)$ & $\boldsymbol{\eta}(\boldsymbol{\%})$ \\
\hline Naked & 1532 & - \\
$0 \%$ & 1452 & 5.51 \\
$3 \%$ & 2063 & 25.74 \\
$6 \%$ & 39443 & 96.12 \\
$9 \%$ & 5257 & 70.86 \\
$12 \%$ & 734 & 8.72 \\
\hline
\end{tabular}

\subsection{Potentiodynamic polarization study}

The study of polarization was utilized to analyze the impact of the presence of LLE in the coating of the immersed mild steel in seawater under room temperature. The data recorded for a different type of coated and uncoated substrates were used to construct the Tafel plots as shown in Figure 4, whereas its corresponding electrochemical parameters were sorted 
out in Table 4. Both data show a promising prospect on the capability of coating produces in reducing the progress of corrosion. From Table 4 and Figure 4, the values of corrosion current density, $i_{\text {corr }}$ are seen to gradually decrease as the concentration of LLE in the coatings increase. Furthermore, the $i_{\text {corr }}$ for both $6 \%$ and 9\% LLE coating are significantly lower as compared to the naked or blank sample indicating a high protective capability than the naturally formed oxide layer on the metal surface. The slopes of all analyzed samples also do not show any systematic change in their inhibitive mechanism. However, the steep decrease in the value of $i_{\text {corr }}$ proved that the coating acts and follow the trend of a mixed type inhibitor. This type of inhibition where it co-occurs on both anodic and cathodic sites will decrease the rate of anodic metal dissolution and cathodic hydrogen evolution reactions. Moreover, the addition of 6\% LLE showed a significant shift of $E_{\text {corr }}$ towards more positive value due to the dominant action on the anodic site which suggest that the coating layer acts as a passive layer preventing from further penetration of corrosive agents. Additionally, the mixed type inhibitor mechanism of the coated layer could also be due to the presence of organic compounds in LLE such as phenolic compounds, protein and amino acid where most of it is known to possess heteroatoms, $\pi$ bond and also aromatic rings. These part of the compounds, when placed in the presence of the aggressive medium, will be in the form of neutral molecules or protonated. When this situation arises, the neutral molecules will both act on anodic and cathodic site by adsorption process to reduce both metal dissolution and hydrogen evolution, respectively through $\pi$ electrons, lone pair of electron and heteroatoms. The lowest corrosion rate obtained was $0.2791 \mathrm{~mm} /$ year of $6 \%$ LLE coating, which agrees with the previous analysis of EIS.

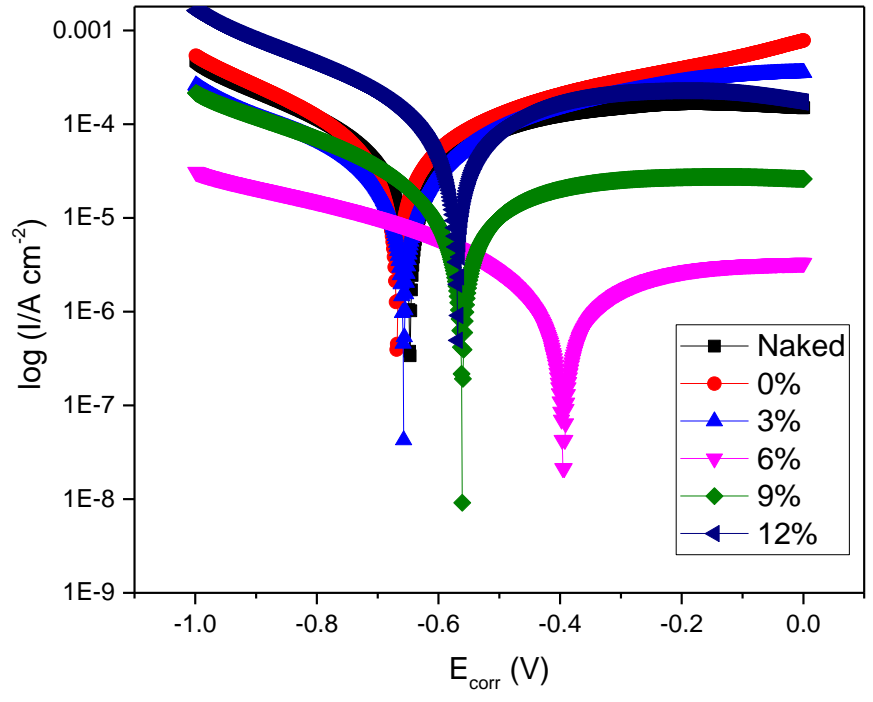

Figure 4. Tafel plot for coated and uncoated mild steels immersed in seawater. 
Table 4. Corrosion parameter of coated and uncoated mild steels immersed in seawater.

\begin{tabular}{cccc}
\hline Sample & $\begin{array}{c}-\boldsymbol{E}_{\text {corr }} \\
(\mathbf{m V})\end{array}$ & $\begin{array}{c}\boldsymbol{i}_{\text {corr }} \\
\left(\mathbf{A ~ c m} \mathbf{~ c m}^{-\mathbf{2}}\right.\end{array}$ & $\begin{array}{c}\text { Corrosion Rate, CR } \\
(\mathbf{m m} / \text { year })\end{array}$ \\
\hline Naked & 650.1 & $2.06 \mathrm{E}-04$ & 2.3991 \\
$0 \%$ & 668.5 & $1.01 \mathrm{E}-04$ & 1.1733 \\
$3 \%$ & 657.3 & $5.71 \mathrm{E}-05$ & 0.6633 \\
$6 \%$ & 394.4 & $2.49 \mathrm{E}-05$ & 0.2791 \\
$9 \%$ & 561.0 & $3.75 \mathrm{E}-05$ & 0.4361 \\
$12 \%$ & 571.2 & $1.20 \mathrm{E}-04$ & 1.3990 \\
\hline
\end{tabular}

\subsection{Surface characterization}

The observation on the surface morphology via SEM/EDS has become one of a major technique concerning the analyzation process of corroded and un-corroded substrates. In this study, the surface condition and the distribution of the corresponding elements of coated mild steel after immersion in seawater for 240 hours at room temperature were observed and carefully examined. To further confirm the capability of the coating produced, observation on both flat surface and cross-sectional area were recorded.

Figure 5(a) shows the SEM images of a freshly polished mild steel after carefully cleaned using acetone and rinsed with distilled water. The polished mild steel possesses a notably smooth surface with a few scratches which can be attributed to the polishing process earlier. Figure 5(b) shows the surface of naked mild steel after the test in seawater has been conducted. The surface in the absence of coating can be determined to have been severely damaged with a lot of deposited materials and pores arising due to an intensive dissolution of metal. Figure 5(c) and 5(d) show the surface of the coating on mild steels with a concentration of $0 \%$ and $6 \%$ of LLE, respectively. Although both images show a better condition when compares to the previous Figure 5(a) and 5(b), the differences are plain to see. Figure 5(c) have a rougher surface and more salt deposition in contrast to Figure 5(d), which has a smooth surface with a minor amount of salt deposition. The observation also correlates with the study of elemental distribution as shown in Figure 7(a-f) as the distribution of element $\mathrm{Na}$ and $\mathrm{Cl}$ in Figure 7(e) and 7(f) proved the existing of salt deposition on the surface of the coating. Moreover, through Figure 7(c) and $7(\mathrm{~d})$, it can be assumed that the accumulation of corrosion product has also occurred in lower intensity. However, notably, huge differences in Figure 5(d) suggest that the presence of an optimum concentration does not only decreases the amount of deposited material but also ensure the coating to stay intact and does not easily crack causing exposure of the protected surface. This is also evident from Figure 6(c) where the coating layer appears to be in good shape and does not possess any crevices. Moreover, in Figure 6(c), a single smooth layer with less damage appeared to be directly underneath the 
coating layer, which shows a good sign of the coating protective capability. The differences can be ascribed to the optimum concentration of LLE, which is $6 \%$ where these results are systematically in agreement with the cross-sectional area observation in Figure 6 as well as all the previous analysis.
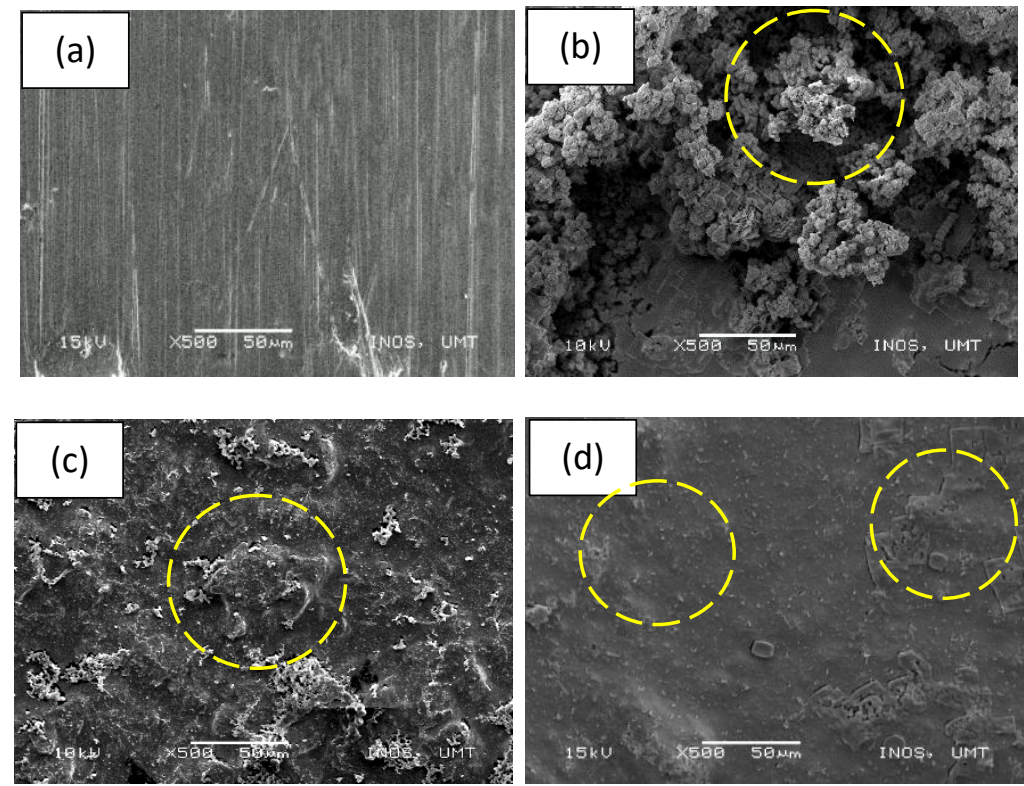

Figure 5. SEM images of (a) freshly polished mild steel coupon, (b) naked mild steel, (c) mild steel with $0 \%$ LLE coating and (d) mild steel with $6 \%$ LLE coating after 240 hours of immersion in seawater.
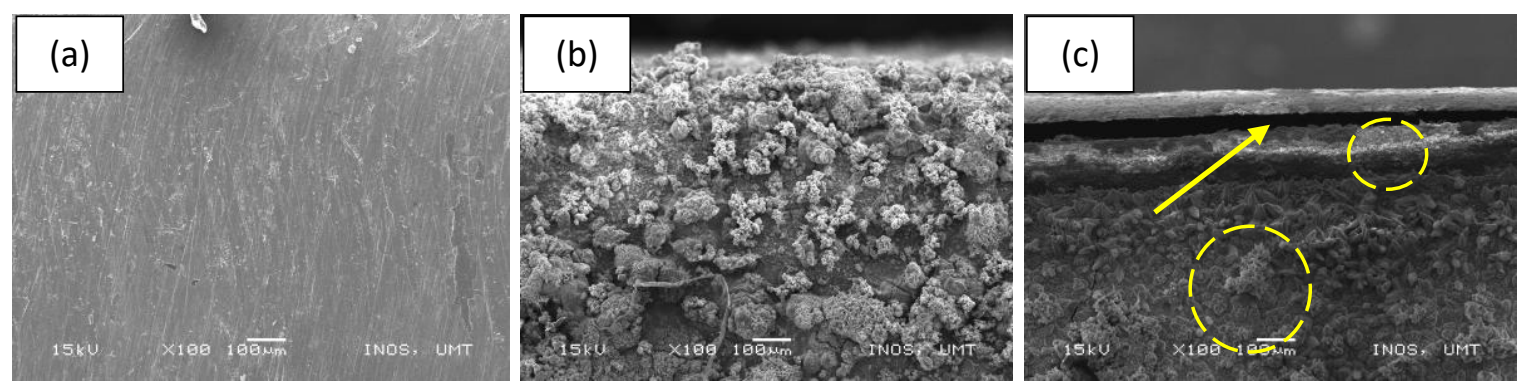

Figure 6. SEM images of the cross-sectional area of (a) freshly polished mild steel coupon, (b) naked mild steel and (c) mild steel with 6\% LLE coating after 240 hours of immersion in seawater. 

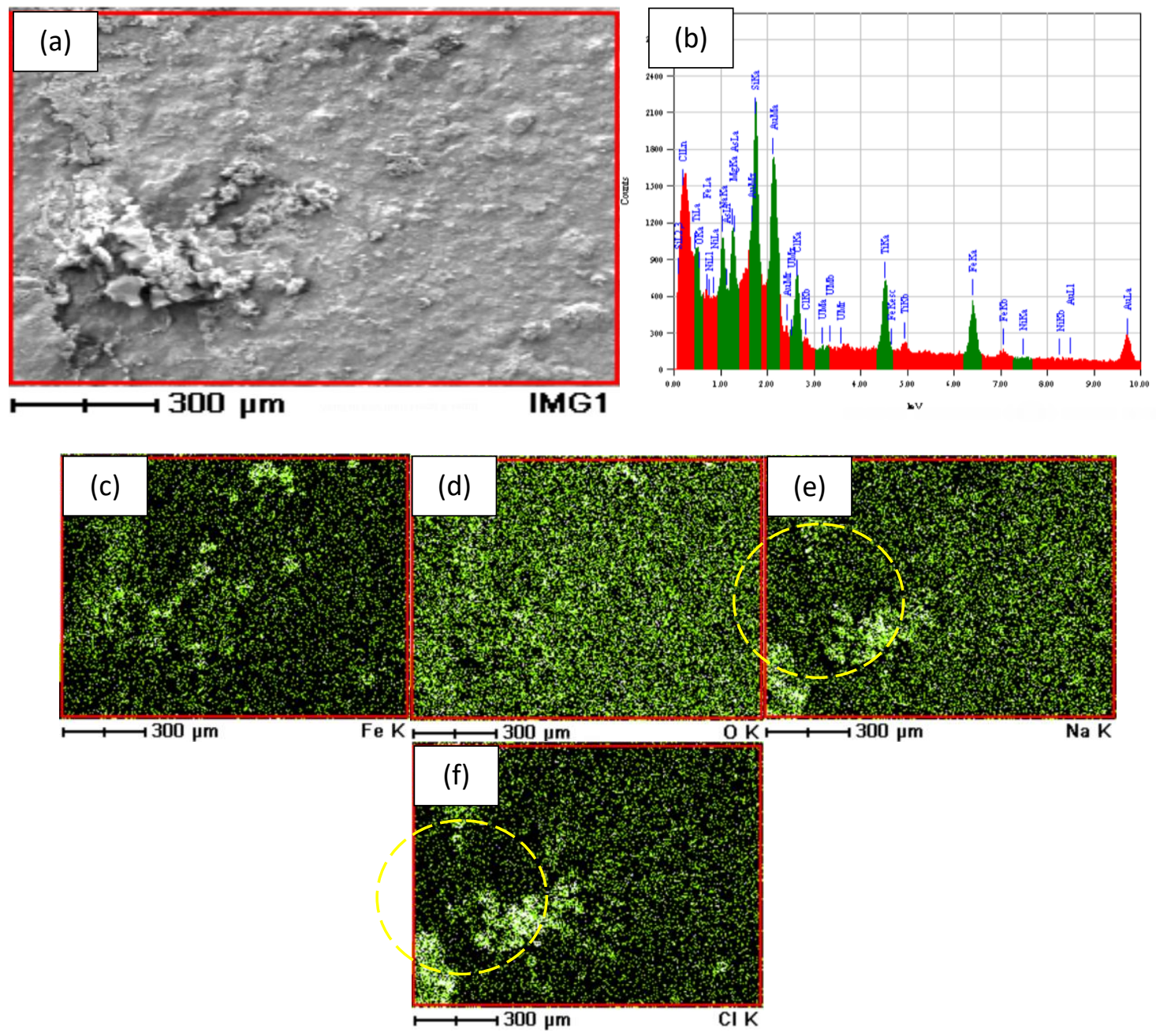

Figure 7. Surface analysis of a coated mild steel exposed to seawater for 240 hours: (a) SEM image; (b) EDS spectrum; (c-f) the distributions of elements $\mathrm{Fe}, \mathrm{O}, \mathrm{Na}$ and $\mathrm{Cl}$.

\section{Conclusion}

The conclusion based on the research conducted are as follows:

1. The coating produced by integrating the extract of river tamarind with a local paint proved to be successful and able to protect the mild steel against the damage of corrosion to a certain extent when immersed in seawater.

2. Analysis via FTIR confirms the presence and the involvement of several functional groups such as hydroxyl and carbonyl groups which proposedly supplies the neutral molecules for the inhibition mechanism.

3. The analysis conducted through electrochemical studies indicates that the efficiency of the coating increases with the increase of LLE concentration until a particular limitation or optimum value is achieved. On the other hand, the study also implies that the coating acts as a mixed type inhibitor where it reduces the progress of corrosion on both anodic and cathodic site. 
4. Based on the observation via SEM, the surface of the coating with the optimum concentration of LLE shows a smooth and well-distributed layer with no sign of cracks and pores indicating the improvement in its capabilities when compared to the observation of the same coating without the presence of extract. This demonstrates a remarkable used of natural resources as a viable method in improving the present corrosion inhibitor.

\section{Acknowledgments}

The authors gratefully thank the financial support of the Fundamental Research Grant Scheme (Vot no. 59537). The authors also extend an appreciation for the support of analytical analysis and testing center of Universiti Malaysia Terengganu.

\section{References}

1. A.I. Ali and Y.S. Mahrous, Corrosion inhibition of c-steel in acidic media from fruiting bodies of Melia azedarach L Extract and a synergistic $\mathrm{Ni}^{2+}$ additive, RSC Adv., 2017, 7, 23687-23698.

2. K. Zakowski, M. Narozny, M. Szocinski and K. Darowicki, Influence of water salinity on corrosion risk - The case of the southern Baltic Sea coast, Environ. Monit. Assess., 2014, 186, 4871-4879.

3. B. Valdez, J. Ramirez, A. Eliezer, M. Schorr, R. Ramos and R. Salinas, Corrosion assessment of infrastructure assets in coastal seas, J. Mar. Eng. Technol., 2016, 15, $124-134$.

4. J.R. Davis, in Corrosion: Understanding the Basics, Ohio, 2000, p. 563.

5. S. Adejo, S. Yiase, U. Ahile, T. Tyohemba and J. Gbertyo, Inhibitory effect and adsorption parameters of extract of leaves of Portulaca oleracea of corrosion of aluminium in $\mathrm{H}_{2} \mathrm{SO}_{4}$ solution, Arch. Appl. Sci. Res., 2013, 5, 25-32.

6. A. Fouda, H. Gadow and K. Shalabi, Chemical and electrochemical investigations of coffee husk as green corrosion inhibitor for aluminum in hydrochloric acid solutions, Int. J. Appl. Sci. Res. Rev., 2015, 23, 28-45.

7. C. Loto, Plants extracts corrosion inhibition of aluminium alloy in $\mathrm{H}_{2} \mathrm{SO}_{4}$, Can. J. Pure Appl. Sci., 2012, 6, 1973-1980.

8. A. Rajendran and C. Karthikeyan, The inhibitive effect of extract of flowers of Cassia auriculata in $2 \mathrm{M} \mathrm{HCl}$ on the corrosion of aluminium and mild steel, Int. J. Plant Res., 2012, 2, 9-14.

9. K. Shalabi, A. Fouda, G. Elewady and A. El-Askalany, Adsorption and inhibitive properties of Phoenix dactylifera 1. extract as a green inhibitor for aluminum and aluminum-silicon alloy in HCl, Prot. Met. Phys. Chem. Surf., 2014, 50, 420-431.

10. A. Singh, Y. Lin, W. Liu, S. Yu, J. Pan, C. Ren and D. Kuanhai, Plant derived cationic dye as an effective corrosion inhibitor for 7075 aluminum alloy in $3.5 \% \mathrm{NaCl}$ solution, J. Ind. Eng. Chem., 2014, 20, 4276-4285. 
11. K. Xhanari, M. Finšgar, M.K. Hrnčič, U. Maver, Ž. Knez and B. Seiti, Green corrosion inhibitors for aluminium and its alloys: a review, RSC Adv., 2017, 7, 27299-27330.

12. L. Bai, L.-J. Feng, H.-Y. Wang, Y.-B. Lu, X.-W. Lei and F.-L. Bai, Comparison of the synergistic effect of counterions on the inhibition of mild steel corrosion in acid solution: electrochemical, gravimetric and thermodynamic studies, RSC Adv., 2015, 5, $4716-4726$.

13. M. Bobina, A. Kellenberger, J.-P. Millet, C. Muntean and N. Vaszilcsin, Corrosion resistance of carbon steel in weak acid solutions in the presence of 1-histidine as corrosion inhibitor, Corros. Sci., 2013, 69, 389-395.

14. A. Fouda, M. Diab and S. Fathy, Role of some organic compounds as corrosion inhibitors for 316L stainless steel in $1 \mathrm{M} \mathrm{HCl}$, Int. J. Electrochem. Sci., 2017, 12, 347362.

15. C. Verma, M. Quraishi, L. Olasunkanmi and E.E. Ebenso, L-proline-promoted synthesis of 2-amino-4-arylquinoline-3-carbonitriles as sustainable corrosion inhibitors for mild steel in $1 \mathrm{~m}$ hcl: experimental and computational studies, RSC Adv., 2015, 5, 85417-85430.

16. B. Xu, Y. Ji, X. Zhang, X. Jin, W. Yang and Y. Chen, Experimental and theoretical studies on the corrosion inhibition performance of 4-amino-N,N-di-(2-pyridylmethyl)aniline on mild steel in hydrochloric acid, RSC Adv., 2015, 5, 56049-56059.

17. H. Alkhathlan, M. Khan, M. Abdullah, A. AlMayouf, A.Y. Badjah-Hadj-Ahmed, Z. AlOthman and A. Mousa, Anticorrosive assay-guided isolation of active phytoconstituents from Anthemis Pseudocotula extracts and a detailed study of their effects on the corrosion of mild steel in acidic media, RSC Adv., 2015, 5, 5428354292.

18. A.-F.Z. Salem, M.Z. Salem, M. Gonzalez-Ronquillo, L. Camacho and M. Cipriano, Major chemical constituents of Leucaena Leucocephala and Salix Babylonica leaf extracts, J. Trop. Agric., 2011, 49, 95-98.

19. S. Chotchutima, S. Tudsri, K. Kangvansaichol and P. Sripichitt, Effects of sulfur and phosphorus application on the growth, biomass yield and fuel properties of Leucaena (Leucaena leucocephala (Lam.) de Wit.) as bioenergy crop on sandy infertile soil, Agric. Nat. Resour., 2016, 50, 54-59.

20. P. Negi, B.S. Rawat and D.S. Negi, Antifeedant constituents from Leucaena leucocephala, J. Appl. Pharm. Sci., 2016, 6, 28-31.

21. M.Z. Zayed and B. Samling, Phytochemical constituents of the leaves of Leucaena leucocephala from Malaysia, Int. J. Pharm. Pharm. Sci., 2016, 8, 174-179.

22. P. Beeharry and B. Surnam, Atmospheric corrosion of welded mild steel, Mater. Today Proc., 2018, 5, 7476-7485.

23. M. Prabakaran, S.H. Kim, V. Hemapriya, M. Gopiraman, I.S. Kim and I.M. Chung, Rhus verniciflua as a green corrosion inhibitor for mild steel in $1 \mathrm{M} \mathrm{H}_{2} \mathrm{SO}_{4}, R S C A d v$., 2016, 6, 57144-57153. 
24. Z. Chen, C. He, F. Yu and Y. Wang, Study and application of electrochemical impedance spectroscopy for quickly evaluating the performance of coatings and predicting the failure time in the development of waterborne epoxy micaceous iron oxide coatings, Int. J. Electrochem. Sci., 2017, 12, 2798-2812.

25. F. Lu, B. Song, P. He, Z. Wang and J. Wang, Electrochemical impedance spectroscopy (EIS) study on the degradation of acrylic polyurethane coatings, RSC Adv., 2017, 7, 13742-13748.

26. R. Patil, B. Sharma and P. Mahanwar, Corrosion performance of hybrid epoxy resin coatings with electrochemical impedance spectroscopy, Pelagia Res. Lib., 2012, 3, $458-467$.

27. W. Ikhmal, M. Yasmin, M. Fazira, W. Rafizah, W.W. Nik and M. Sabri, Anticorrosion Coating using Olea sp. Leaves Extract, in IOP Conf. Ser. Mater. Sci. Eng. 2018. Universiti of Lampung, ID: IOP Publishing.

28. W.M. Doyle, Principles and applications of Fourier Transform Infrared (FTIR) process analysis, Proc. Cont. Qual., 1992, 2, 11-41.

29. M. Yu, X. Zhao, L. Xiong, B. Xue, X. Kong, J. Liu and S. Li, Improvement of corrosion protection of coating system via inhibitor response order, Coatings, 2018, 8, 365. 